\title{
DERECHO SUBJETIVO, NATURALEZA Y DOMINIO EN FRANCISCO DE VITORIA*
}

\author{
SUBJECTIVE RIGHTS, NATURE AND DOMINIUM \\ IN FRANCISCO DE VITORIA
}

\section{RESUMEN}

En la teoría de los derechos naturales subjetivos de Francisco de Vitoria confluyen dos tradiciones distintas en torno al concepto de derecho. De un lado, el realismo tomista que adopta la concepción romana y romanista del derecho entendido como determinación de la cosa justa. Del otro, la nominalista, que incorpora una concepción subjetivista del derecho. En este trabajo analizamos la relación entre derecho subjetivo, ley natural, dominio y propiedad en Francisco de Vitoria en el contexto de una trayectoria que arranca de la creencia estoica en un estado de naturaleza y que, inserta en la tradición romanista medieval, fue adoptada por la teología cristiana como teoría sobre el origen de las instituciones.

Palabras clave: estado de naturaleza, derecho subjetivo, dominio, Francisco de Vitoria, propiedad.

* Este trabajo es resultado del proyecto ““'Sociedad, política y economía: proyecciones de la Escolástica española en el pensamiento británico y anglosajón'”' (Programa Estatal de Fomento de la Investigación Científica y Técnica de Excelencia. MINECO, AEI, FEDER. Referencia: FFI201784435-P). El autor agradece los comentarios de la Dra. $\mathrm{D}^{\mathrm{a}}$ Lorena Velasco Guerrero y de los evaluadores que han contribuido a mejorar este trabajo. 


\section{ABSTRACT}

In Francisco de Vitoria's theory of subjective natural rights two different traditions around the nature of law converge. On the one hand, the Thomist realism that adopts the Roman and Romanist conception of law understood as the determination of the just thing. On the other, a nominalist concept which embodies a subjective conception of law. In this work, we analyze the relationship between subjective rights, natural law, dominium and property in Francisco de Vitoria in the intellectual framework of a trajectory that begins with the stoic belief on a state of nature and which, inserted in the medieval Romanist tradition, was adopted by the Christian theology as a theory of the origin of institutions.

Keywords: dominium, Francisco de Vitoria, property, subjective rights, state of nature.

\section{INTRODUCCIÓN}

El pensamiento escolástico asume el derecho romano, así como el doble origen de la ley: natural y positivo. A estas leyes añade una tercera, la divina ( $e$. g. el Decálogo y la Ley Evangélica) que no se impone a las otras dos, sino que las integra coherentemente. De esta integración da buena cuenta la Suma Teológica (STh) de santo Tomás ${ }^{1}$ aunque la influencia jurídica de Roma queda también patente en el derecho canónico, en la propia organización de la Iglesia y en el Ius Commune medieval. A pesar del realismo jurídico y filosófico del tomismo de la Escuela de Salamanca, están presentes en ella elementos de subjetivismo jurídico ${ }^{2}$ que, según la tesis de Tierney $^{3}$, el nominalismo habría

1 Jean-Marie Aubert, Le droit romain dans l'œeuvre de saint Thomas (Paris: Vrin, 1955).

2 Truyol afirma que Roma ya conocía el concepto de derecho subjetivo "en cuanto reflejo de un estatuto o bajo la forma de prerrogativas (iura) derivadas del Derecho como norma": Antonio Truyol, Historia de la filosofia del Derecho y del Estado (Madrid: Alianza, 1995), 418. Hay que diferenciar la presencia de derechos subjetivos de una concepción subjetivista del derecho que, a su vez, puede tener un origen natural o positivo.

3 Ver Brian Tierney, The idea of natural rights (Grand Rapids, Michigan: William B. Eerdmans Publishing Company, 1997). Por otra parte, la abundancia de derechos subjetivos en el derecho canónico obedecería al deseo de la Iglesia, tras el Concordato de Worms (1122), de delimitar con precisión su potestas jurisdiccional frente a otras instancias rivales (imperial, real, feudal, señorial, urbana, mercantil) en un proceso que se inicia con la reforma gregoriana y que Harold J. Berman (The Formation of the Western Legal Tradition (Cambridge, Mass: Harvard University Press, 1983) califica de "revolución del papado". La tradición legal occidental iniciada entonces se caracterizaría por la pretensión de elaborar conscientemente sistemas legales internamente coherentes, por la sujeción a la ley de toda instancia de poder y por la fundamentación del derecho en principios de justicia y razón. La pluralidad de jurisdicciones en la etapa que media entre los siglos XII y XVII encuentra su paralelo en 
importado del derecho canónico. En Francisco de Vitoria, debido a su formación en la Universidad de París, y en otros miembros de la Escuela se encuentran tanto un concepto de derecho entendido como ius, ligado a su concepción romana y romanista, como también en forma de facultas o potestas. ${ }^{4} \mathrm{El}$ predominio progresivo de una concepción subjetivista del derecho se produce por medio de la identificación de ius y dominium. El dominio es una potestad que se atribuye a un sujeto creando una esfera de autonomía donde puede ejercer determinadas acciones (como las propias de la jurisdicción de un gobernante) o usar de ciertas cosas (licita facultas utendi). Dicha potestad trae consigo obligaciones y/o prohibiciones con respecto a otros sujetos siendo éste el modo en que se reconoce el dominio. Según se especifique el dominio sobre personas o sobre cosas materiales e inmateriales, las instituciones fundamentales de una sociedad -la propiedad, la familia, el poder político- adoptan determinadas formas. El dominio terminará identificándose con un derecho $a \mathrm{y}$, en consecuencia, el sujeto pasará a ser sujeto de derechos, bien activos (como las libertades de), bien pasivos (derechos a que otros hagan, por ejemplo, prestarme servicios sanitarios).

La concepción del derecho como derecho subjetivo, específica de la cultura cristiana, se fue imponiendo desde el medievo tardío. Si bien Villey ${ }^{5}$ atribuye el origen conceptual del derecho subjetivo a Ockham, Tierney ${ }^{6}$ lo sitúa en la jurisprudencia canónica, de donde éste lo habría tomado con motivo de la polémica sobre la pobreza evangélica que enfrentó a la orden franciscana con el papado. La teoría del derecho subjetivo está presente, entre otros, en los nominalistas Jean Gerson y Conrado de Summenhart ${ }^{7}$, a quienes Francisco de Vitoria cita con frecuencia. Vitoria conoce el nominalismo en la Universidad de París ("mitigado y ecléctico" según García Villoslada ${ }^{8}$ ) donde se encontraban John Maior

la diversidad de legalidades (ley divina, tanto Antigua como Nueva, ley natural y leyes positivas) que era preciso armonizar respetando sus identidades.

4 Jaime Brufau, "La noción analógica del dominium en Santo Tomás, Francisco de Vitoria y Domingo de Soto". Salmanticensis 4, n. 1 (1957): 96-136; Avelino Folgado, "La controversia sobre la pobreza franciscana bajo el pontificado de Juan XXII y el concepto de derecho subjetivo". Pax iuris. Escurialensium utriusque studiorum excerpta (1959): 73-133; Annabel S. Brett, Liberty, right and nature: individual rights in later scholastic thought (Cambridge: Cambridge University Press, 1997); Alejandro Guzmán Brito, El derecho como facultad en la Neoescolástica española del siglo XVI (Madrid: Iustel, 2009); Francisco T. Baciero, "El concepto de derecho subjetivo y el derecho a la propiedad privada en Suárez y Locke". Anuario filosófico 45, n. 2 (2012): 391-421.

5 Michel Villey, La formation de la pensée juridique moderne (París: PUF, 1975).

6 Tierney, The idea of natural rights.

7 Guzmán Brito, El derecho como facultad; Jörg Alejandro Tellkamp, "Ius est idem quod dominium: Conrado Summenhart, Francisco de Vitoria y la conquista de América", Veritas 54, n. 3 (2009): 34-51.

8 La Universidad de París durante los estudios de Francisco de Vitoria. Véase también, Belda, La Escuela de Salamanca. 
(influido por Gerson), Jacques Almain, los hermanos Coronel o Juan de Celaya, maestro suyo.

Para Gerson el derecho es "facultad o potestad inmediata que conviene a alguien según el dictamen de la recta razón" o también según "la justicia primera" 10 . Todo ente por tener entidad (y por ello bondad, ya que, en el bien ontológico, ser y bien son equivalentes) tiene derecho. La facultad, el derecho $a$, no se predica solo del ente racional, sino de toda substancia de la que constituye una cualidad. De esta manera, el cielo tiene derecho a desaguar, el sol a iluminar, el fuego a calentar y así el resto de las criaturas. ${ }^{11}$ Se trata de un derecho subjetivo dictado por la naturaleza de cada cosa, necesario por tanto. Por ello también es de derecho natural -subjetivo- que el hombre, incluso el pecador, tenga derecho a muchas cosas como cualquier otra criatura abandonada a su naturaleza. ${ }^{12}$ En definitiva, el hombre goza de derecho por ley natural.

En este trabajo analizamos la relación entre derecho subjetivo, ley natural y dominio en Francisco de Vitoria en el contexto de una trayectoria que arranca de la creencia en un estado de naturaleza, inserto en la tradición romanista medieval y adoptado por la teología cristiana como teoría sobre el origen de las instituciones. Para ello procedemos del siguiente modo. La sección primera presenta las notas fundamentales de la ley natural conforme a lo expuesto por santo Tomás y que Vitoria asume plenamente al comentar la Suma. Por ser fuente de equívocos y por su relevancia teórica, hay que diferenciar un concepto de derecho natural que se interpreta como aquel vigente en el estado de naturaleza, de la concepción de ley natural como cierta regla del derecho -en tanto ley-que el Aquinate identifica con determinadas tendencias innatas presentes en el hombre y que la ley positiva debe asumir. La distinción entre derecho y ley que sostienen el Aquinate y Vitoria es relevante, pues la identificación de ius y dominium discurre en paralelo a la de ius y lex, de modo que a día de hoy las leyes constituyen básicamente recopilaciones de derechos.

El reconocimiento de derechos subjetivos se produce en Vitoria en el seno del derecho natural (constituyen derechos naturales subjetivos) por lo que es

$9 \quad$ Liber de vita spirituali animae, lect. 3.

10 Tractatus de potestate ecclesiastica, consid. 13.

11 Vitoria niega derecho a las criaturas irracionales: "las criaturas irracionales no pueden tener dominio ...porque dominio significa derecho, como enseña Conrado. Ahora bien las criaturas irracionales no pueden tener derecho. Luego tampoco pueden tener dominio ...porque no pueden padecer injuria”, en De indis, 20. En lo sucesivo, seguimos la edición completa de las relecciones editada por la editorial San Esteban en 2017.

12 Alejandro Guzmán Brito, "La doctrina del derecho-facultad o potestad de Francisco de Vitoria". En Francisco de Vitoria en la Escuela de Salamanca y su proyección en Nueva España, editado por V. Aspe y M. I. Zorroza. Pamplona: Eunsa, 2014. 
preciso abordar la naturaleza de éste y su íntima relación con el derecho de gentes, en el que queda determinado el derecho natural y que cuenta también con la característica de universalidad. Precisamente, la innovación vitoriana en torno al derecho de gentes en la relección De indis (1539) es un ejemplo paradigmático de este tipo de determinación. El dominio es una institución de derecho natural, no sobrenatural, y que, por serlo, no se pierde por infidelidad o pecado. Como afirma el Aquinate, "lo que es natural en el hombre ni se le añade ni se le retira por el pecado" ". En coherencia con ello, Vitoria en De indis rechaza el argumento que negaba capacidad de dominio a los indios por infieles. Al ser el dominio de origen natural, estamos ante un derecho natural subjetivo: gracias a él, los indios cuentan por naturaleza con dominio, esto es, con derecho a autogobernarse y administrar sus bienes. Además del autogobierno de las comunidades políticas, son derechos naturales subjetivos el derecho a tomar lo que se precise en caso de extrema necesidad, dado que, cuando la vida peligra, las cosas vuelven a ser comunes -stricto sensu nunca dejaron de serlo-; o también los derechos a comunicarse y comerciar con otros pueblos, al libre tránsito y a la navegación marítima; así como los justos títulos derivados de un principio natural de legítima defensa que otorgan derecho $a$ la guerra. ${ }^{14}$

En la sección segunda se aborda la relación entre estado de naturaleza, dominio y propiedad. La tradición cristiana adopta como suya la creencia estoica en un estado primigenio donde regían una igualdad y libertad naturales. Creencia compatible, en principio, con la concepción cristiana de lo que podría haber sido el estado de naturaleza previo a la Caída. El dominio sobre las cosas le corresponde al hombre por ser creado a imagen de Dios ${ }^{15} \mathrm{y}$ adopta, antes del pecado, la forma de propiedad común por ser este el modo en que mejor se realiza la equidad natural según Vitoria. Sin embargo, habida cuenta del estado de naturaleza en que se encuentra el hombre tras la Caída, se hacen necesarios tanto la división de las cosas como el gobierno humano en sus variadas formas. La luego denominada propiedad privada surge como desarrollo conveniente -determinación- de la ley natural, realizado por el derecho de gentes, que adapta al estado de naturaleza caída el dominio sobre las cosas otorgado por Dios (sección tercera). A diferencia de lo afirmado por Escoto, santo Tomás y Vitoria niegan que la ley natural quede revocada por el pecado, pues éste no destruye la naturaleza. De ahí que el dominio y la propiedad común, que son de derecho natural, no estén derogados, aunque en nuestro estado se opte preferentemente - sin

13 STh I, c. 98, a. 2.

14 En la relección De iure belli Hispanorum in barbaros de 1539.

15 En Gn. 1:26: "Dios dijo: "Hagamos al hombre a nuestra imagen, según nuestra semejanza; y que le estén sometidos los peces del mar y las aves del cielo, el ganado, las fieras de la tierra, y todos los animales que se arrastran por el suelo". 
exclusividad, no obstante- por la división de las propiedades. Por último, presentamos las conclusiones del trabajo.

\section{LEY NATURAL, DERECHO NATURAL Y SU DETERMINACIÓN POR EL DERECHO DE GENTES}

El derecho surge tanto para crear posibilidades de acción como para prevenir y resolver conflictos, no de cualquier modo, sino con justicia. Debido a lo primero, reduce la incertidumbre sobre las acciones que esperamos de los demás, lo que permite llevar a cabo con cierta confianza las actividades cotidianas propias de la vida familiar, el trabajo, los negocios, etc. Debido a lo segundo, contribuye a resolver los conflictos que surgen habitualmente en la convivencia humana evitando escaladas de represalias que harían imposible la vida en sociedad. En tanto solución jurídica, el derecho previene o resuelve, hasta donde es humanamente posible, un contencioso potencial o efectivo. Ante un determinado $\operatorname{caso}^{16}$, el jurista, en un ejercicio que combina inducción desde los hechos y deducción desde las leyes, procura realizar lo justo. Ley (lex) y derecho (ius) no se identifican: para el pensamiento de inspiración tomista, la ley es una regla a la que ajustarse, es cierta razón o causa del derecho. ${ }^{17}$

La solución jurídica es práctica y combina la generalidad de las leyes con la singularidad del caso. En la terminología de la Escuela de Salamanca, se trata de un juicio probable en tanto solución admisible o razonable frente a otras que también podrían serlo. Subyace la idea de que no hay un solo camino para realizar lo justo y que debe elegirse el que más probablemente conduzca hacia ello. Las soluciones jurídicas son falibles y pueden cambiar dependiendo de las diversas circunstancias. Para llegar al ius es preciso el uso de la recta razón, dado que el propio actuar humano produce profusión de casos singulares,

16 Conforme a Carpintero, la jurisprudencia clásica, en lugar de promulgar leyes nuevas para cosas nuevas, como sucede actualmente, procedía a una argumentación basada en la extensión analógica y en la derogación. Para el Ius Commune, en el juicio práctico el razonamiento comienza desde los hechos y finaliza en las normas. Por ello sus manuales se presentaban como la determinación de las soluciones que correspondían a cada caso y raramente aparecían digresiones sobre los tipos de leyes a que debía acogerse cada solución. La ley existe en función del derecho, y es desde éste desde donde debe estudiarse la mutación, la variabilidad o la capacidad de adaptación de las leyes. Actualmente el derecho se ha transformado en legislación. Este cambio de concepción se empieza a manifestar en los tratados de los escolásticos españoles tardíos que solían comenzar por la descripción de las leges al entender que éstas constituían la especie más general del derecho. Ver Francisco Carpintero, La ley natural. Historia de un concepto controvertido (Madrid: Encuentro, 2008)

17 Mauricio Beuchot, "La Ley y el Derecho en Santo Tomás", Revista de Filosofia 24, n. 2 (1996): 109-127. 
impredecibles en buena medida, que las leyes no pueden anticipar. ${ }^{18}$ No obstante lo dicho, la posibilidad de generalizar casos iguales en un aspecto esencial remite a la existencia de una naturaleza de las cosas y a unas normas -las leyesque implican la misma solución ante unas circunstancias que éstas se encargan de tipificar.

Bajo una concepción subjetivista del derecho se procede a deducir sistemas completos de derechos al margen de un caso; en su lugar se presupone un contencioso generalizado entre grupos humanos. Así, en el pensamiento de Vitoria y de la Escuela de Salamanca se reconocen diversos derechos naturales subjetivos en respuesta a un contencioso con los indios (la duda indiana) o que deben prevalecer en caso de guerra. Por naturales, los derechos de los indios o de los enemigos están ahí (impresos "en el corazón de los hombres"19) por lo que no necesitarían de un acto explícito de promulgación para ser respetados. ${ }^{20}$

El reconocimiento de principios generales que son de aplicación a multitud de contenciosos y que se perciben como evidentemente justos, remite a la existencia de una ley natural integradora de diversas tendencias universales. Así, por ejemplo, la tendencia a la conservación y perpetuación de la vida, a la sociabilidad, el deseo de paz y concordia, la búsqueda de la trascendencia, de la equidad en los diversos tratos, etc. La ley natural se entiende, entonces, como un conjunto de normas inmutables sobre el ser de las cosas que permite diferenciar el bien del mal tanto por paganos como por cristianos. ${ }^{21}$ Para el pensamiento

18 Mediante la aequitas latina, equivalente a la epiqueya griega es posible reconducir las leyes hacia la ley natural en los casos en que su aplicación práctica puede resultar injusta sin que la propia ley, en su universalidad, lo sea. Ver Aristóteles, Ética V, 10; Juan Cruz, "Reconducción práctica de las leyes a la ley natural: la epiqueya". Anuario Filosófico 41, n. 1 (2008): 155-179. No habría falta en la ley ni en el legislador, sino que la singularidad y contingencia de los actos humanos hace imposible al legislador prever todos los casos posibles (STh II-II, c. 120, a. 1). Los legisladores legislan para la mayoría de los casos, pero observar estrictamente la ley en todos los casos puede ir contra la equidad y el bien común, que es precisamente lo que persigue la ley. La epiqueya constituye, así, cierta forma de justicia.

19 Rm. 2:14-15.

20 No es esta la posición de los nominalistas para quienes es preciso diferenciar la ley natural, que es meramente indicativa (lex indicans), del deber de cumplirla (lex imperans) que surge tras un acto imperativo de la voluntad, bien de Dios para la ley divina, bien del gobernante para las leyes positivas. No obstante, para Gregorio de Rimini, la vulneración de la ley natural, aún si Dios no existiera o errara, sería pecado al ir contra la recta razón. De este modo se concede autonomía a la ley natural respecto de la ley divina, lo que posteriormente admitirán Gabriel Vázquez y Hugo Grocio, entre otros (v. Truyol y Serra, vol. I, p. 420). Por influjo de Suárez, la concepción voluntarista de la ley natural está presente en Grocio y en Locke también en los reformadores protestantes y en autores como Descartes, Spinoza o Pufendorf. Ver Leopoldo Prieto, "La Ley natural y el orden político en John Locke", Revista española de Teología 69, n. 3 (2009): 383-440 y "La noción de ley en Suárez y Locke", Daimon: Revista Internacional de Filosofía 71 (2017): 137-156.

21 Cicerón es la principal fuente de un concepto de ley natural que tendrá suma influencia en los pensadores cristianos. Lactancio (De divinis institutionibus, libro VI, 8) proporciona esta cita, ya 
escolástico de inspiración tomista, ley y razón se identifican en la práctica, puesto que la ley es la razón de las cosas. Para santo Tomás es posible conocer -en un proceso perfectivo- y cumplir toda ley, la regla y medida de las cosas, ya que intelecto y voluntad se orientan como objetos generales a la verdad y al bien $^{22}$, respectivamente, permitiendo aprehender en el orden de la Creación su razón de ser -la naturaleza de las cosas-, en la que reside además su bien.

Francisco de Vitoria ${ }^{23}$ afirma que la ley natural existe en nosotros porque, por inclinación de la naturaleza, juzgamos sobre la rectitud de las cosas, no porque esa cualidad se halle en nosotros por naturaleza. La ley natural cuenta con contenidos específicos, tendencias naturales, de modo que el orden de los preceptos de la ley natural es correlativo al de las inclinaciones naturales del hombre. Al haber muchas inclinaciones naturales, hay muchos principios. ${ }^{24} \mathrm{La}$ inclinación natural obliga; de otro modo, antes de la ley escrita, sería imposible saber, por ejemplo, que suicidarse es pecado. El entendimiento, sin que nadie se lo enseñe, juzga que hay cosas buenas y la voluntad se inclina por naturaleza hacia ellas: "si yo me engañara, sería Dios quien me engañaría, pues él puso en mi esta inclinación" 25 .

Según el Aquinate, la primera inclinación, común a todas las sustancias, es a conservar su propio ser, por lo que corresponde a la ley natural todo aquello que concierne a la conservación de la vida e impide su destrucción. En segundo lugar, existe una inclinación hacia bienes más determinados y que es común con el resto de los animales, como la conjunción de los sexos y la educación de los

clásica, que está en el libro III de la ciceroniana De Republica: "Existe una ley verdadera, la recta razón, conforme a la naturaleza, universal, inmutable, eterna, cuyos mandatos estimulan al deber y cuyas prohibiciones alejan del mal ...Ni el Senado ni el pueblo pueden libertarnos de la obediencia a esta ley. No necesita un nuevo intérprete, o un nuevo órgano: no es diferente en Roma que en Atenas, ni mañana distinta de hoy, sino que en todas las naciones y en todos los tiempos esta ley reinará siempre única, eterna... Dios mismo da el origen, la sanción y la publicidad a esta ley, que el hombre no puede desconocer sin huir de sí mismo, sin desconocer su naturaleza y sin sufrir por esta sola causa la más cruel expiación". Véanse también, entre otras citas, De inventione rethorica II, 161; De legibus I, 1618; I, 42; II, 8; De oficiis III, 72. La ratio summa, insita in natura, es el espíritu mismo de Dios, su razón soberana; mientras que las leyes humanas son tales en tanto participan de ella. Todos los hombres gozan de igual dignidad (humanitas), pues poseen razón y capacidad para diferenciar lo justo de lo injusto. Es evidente la influencia de este principio en la communitas totius orbis de Vitoria.

22 "El conocimiento natural del bien es oscurecido por las pasiones y los hábitos pecaminosos" (STh I-II, c. 93, a. 6), pero en ningún hombre domina la ley de la carne de modo que destruya todo el bien natural que hay en él: siempre queda en el hombre una inclinación a hacer lo que le pide la ley eterna. El pecado no destruye todo el bien de la naturaleza (STh I-II, c. 93, a. 6 ad 2).

23 En De Legibus al comentar la c. 94, a. 1 de la Suma.

24 De Legibus, c. 94, a. 2.

25 De Legibus, c. 94, a. 2. 
hijos, es decir, la tendencia natural a formar una familia. ${ }^{26} \mathrm{Y}$ en tercer lugar, en consonancia con la naturaleza racional del hombre, su inclinación natural a buscar la verdad sobre Dios y a vivir en sociedad ${ }^{27}$, por lo que pertenece a la ley natural todo lo que se derive de esto, como evitar la ignorancia o respetar a los conciudadanos.

La ley humana parte de los preceptos generales e indemostrables de la ley natural llegando a disposiciones singulares que son las propias leyes humanas. La ley humana lo es por derivar de la ley natural, en otro caso es corrupción de la ley. ${ }^{28}$ Esta derivación se produce de dos modos: como conclusión a partir de los principios de la ley natural o como determinación de algo indeterminado. ${ }^{29}$ Las primeras son leyes humanas con fuerza de ley natural, las segundas no tendrían más fuerza que la de la ley humana. Este proceso, que corresponde a la razón práctica, discurre de modo análogo al de la razón especulativa que parte de unos principios indemostrables conocidos de modo natural y obtiene las conclusiones de las diversas ciencias. ${ }^{30}$

En relación al concepto de derecho natural, Ulpiano, que contempla una división tripartita del derecho (natural, de gentes y civil), afirma que el derecho natural es el que la naturaleza ha dado tanto a humanos como a animales e

26 En varias de sus relecciones desarrolla Vitoria estos principios de derecho natural, que hoy denominaríamos de derecho a la vida y de protección de la familia. En De homicidio (1530) parte Vitoria de las inclinaciones naturales a la vida, a Dios y al bien común para tratar temas como el homicidio, el suicidio, la pena de muerte, las situaciones de riesgo para la vida y la eutanasia. De temperantia (1538) trata sobre la conservación de la vida mediante el alimento y de las diversas prohibiciones al respecto condenando los sacrificios humanos y el canibalismo, así como sobre la conservación de la especie y la obligación de procrear. En De matrimonio (1531), escrita con motivo del divorcio de Enrique VIII, se defiende la importancia de la generación y educación de la prole como fin de la institución matrimonial, que es de derecho natural y divino, junto con la ayuda mutua en el seno de la familia. La articulación de la sociabilidad natural del hombre en forma de comunidad política se analiza en De Potestate Civili (1528).

27 La soledad sólo conviene al contemplativo que ya ha llegado a la perfección (STh II-II, c. 188 , a. 8). La naturaleza social o política del hombre se debe al hecho de que un hombre no se basta a sí mismo para vivir, ya que la naturaleza lo ha provisto de muy pocas cosas con suficiencia (Suma contra los gentiles, libro 3, cap. 85). Para conseguir su fin propio, que es la bienaventuranza, es preciso que los hombres se unan con amor mutuo dado que entre quienes tienen un fin común debe existir unión de afectos: el amor a Dios obliga al amor al prójimo. La ley divina de amor al prójimo se ha promulgado en auxilio de la ley natural ya que, de modo natural, un hombre tiende a socorrer a otro en caso de necesidad (Ibíd., libro 3, cap. 117). Obliga además a una ordenada concordia para que los hombres no se estorben unos a otros en la consecución del fin común, que es Dios (Ibíd., libro 3, cap. 128).

28 STh I-II, c. 95, a. 2.

29 Se puede ampliar lo dicho consultando el comentario del Aquinate a la EN de Aristóteles (Sententia Ethic., lib. 5, lectio 12). También en Sebastián Contreras, "La recepción de la doctrina tomista de la determinación del derecho en la segunda Escolástica", Revista Filosófica de Coimbra 45 (2013): 113-146.

30 STh I-II, c. 91, a. 3. 
incluye la unión entre los sexos y la procreación y educación de los hijos ${ }^{31}$, mientras que el derecho de gentes ${ }^{32}$ rige exclusivamente las relaciones entre los hombres. Su contenido queda recogido en Dig. 1.1.5 $5^{33}$. Para Celso el derecho es el arte de lo bueno y lo equitativo ${ }^{34}$ afirmando Paulo que el derecho natural siempre lo es ${ }^{35}$. Por derecho natural todos los hombres nacen libres ${ }^{36}$. La clasificación de Gayo, al igual que la de Aristóteles, es bipartita. Aristóteles ${ }^{37}$ distingue entre un derecho natural, no escrito y común a todos los pueblos (politikon dikaion physikon) y un derecho civil propio de cada pueblo (politikon dikaion nomikon). Por su parte, Gayo ${ }^{38}$ asimila derecho natural y de gentes al suponer que éste último es el que la razón natural instituyó entre los hombres.

Históricamente, el ius gentium resultaba de las decisiones del pretor peregrinus para regular las relaciones entre ciudadanos romanos y extranjeros o bien entre éstos últimos. El ius gentium tiene inicialmente un origen jurisprudencial mientras que la concepción del ius naturale proviene de la filosofía griega por mediación del estoicismo, de ahí que los juristas no se pusieran de acuerdo sobre su contenido. El ius naturale es de naturaleza especulativa y toma como referencia un modelo antropológico determinado (i. e. el de estado de naturaleza) mientras que el ius gentium se refiere a instituciones de vigencia inmemorial, tácita y comúnmente aceptadas por pueblos diversos. El dominio político, la propiedad o la esclavitud son instituciones de derecho de gentes, mientras que el derecho civil es el legislado o el consuetudinario propio de cada comunidad política.

Siguiendo doctrinas estoicas, el derecho natural vendría a corresponderse con el vigente en un estado de naturaleza, etapa primigenia de la humanidad en la que todos eran libres (omnium una libertas), no existiendo por ello relaciones jerárquicas de ningún tipo, y todo era poseído en común (communis omnium

31 Dig. 1.1.1.3.

32 Dig.1.1.1.4.

33 "Ex hoc iure gentium introducta bella, discretae gentes, regna condita, dominia distincta, agris termini positi, aedificia collocata, commercium, emptiones venditiones, locationes conductiones, obligationes institutae: exceptis quibusdam quae iure civili introductae sunt".

34 Dig. 1.1.1pr.

35 Dig. 1.1.11.

36 Dig. 1.1.4; 1.5.4.1; 12.6.64; 40.11.2; 50.17.32.

$37 \quad E N \mathrm{~V}, 1134 \mathrm{~b}, 20-30$.

38 Dig. 1.1.9. 
possessio $)^{39,40}$. De la trascendencia de esta creencia, luego cristianizada, da cuenta su pervivencia en las declaraciones de Derechos Humanos ${ }^{41}$ y en las Constituciones. Bajo la concepción antropológica cristiana, el estado de naturaleza al que conviene el derecho natural encontraría su equivalente en un estado de naturaleza íntegra, previo a la Caída. Los estados de naturaleza íntegra y de Caída son estados de vía hacia el estado de naturaleza glorificada.

Siendo por naturaleza todos los hombres libres e iguales, la pérdida de la libertad e igualdad originarias que parece traer consigo la vida en sociedad se debe a dos razones: i) por necesidad, también natural, derivada de las diversas circunstancias que surgen una vez se abandona el estado originario. Entonces, el poder político, la servidumbre o la propiedad son naturalmente necesarios en el estado de naturaleza caída, pues de otro modo la vida en sociedad sería inviable; y ii) por libre consentimiento en forma de pacto o contrato. Así, por necesidad condicionada a las circunstancias, el derecho de gentes admite la esclavitud de los prisioneros de guerra como alternativa preferible a su sacrificio; $y$,

39 La comunidad de bienes está presente en la literatura clásica inserta en el mito de la Edad de Oro. Además del precedente griego (e. g. Los trabajos y los días de Hesíodo, o su conocida presencia en La República de Platón) podemos citar las referencias romanas de Virgilio (Geórgicas, I, 125 y ss.) y Ovidio (Metamorfosis, I, 89-150). En su Epistola XC (Epistolae morales), Séneca se refiere al siglo de oro en que se compartían los bienes de la tierra y el más sabio gobernaba sin ejercer coacción. Humanistas y literatos modernos revitalizan este mito, así en El Quijote (cap. XI): "Dichosa edad y siglos dichosos aquellos a quien los antiguos pusieron nombre de dorados ...porque entonces los que en ella vivían ignoraban estas dos palabras de tuyo y mío. Eran en aquella santa edad todas las cosas comunes....". Esta tradición, unida al descubrimiento de América donde muchos creyeron ver la pervivencia de la Edad Dorada, terminará conformando otro mito de importancia equiparable, el del buen salvaje. Ver: José Luis Abellán, La edad de Oro (siglo XVI). Tomo 2 de Historia crítica del pensamiento español (Madrid: Espasa Calpe, 1979).

40 El Decreto de Graciano (dist. 1, c. 7) toma las definiciones de derecho natural y de gentes de San Isidoro (Etimologías, libro V) inspiradas en las fuentes romanas mencionadas: "Quid sit ius naturale. Ius naturale est commune omnium nationum, eo quod ubique instinctu naturæ, non constitutione aliqua habetur, ut viri et feminæ coniunctio, liberorum successio et educatio, communis omnium possessio et omnium una libertas, acquisitio eorum, quæ celo, terra mari que capiuntur; item depositæ rei vel commendatæ pecuniæ restitutio, violentiæ per vim repulsio. §. 1. Nam hoc, aut si quid huic simile est, numquam iniustum, sed naturale equum que habetur". Mientras que el ius gentium (Decretum dist. 1, c. 9) "est sedium occupatio, edificatio, munitio, bella, captivitates, servitutes, postliminia, federa pacis, induciae, legatorum non violandorum religio, conubia inter alienigenas prohibita. §. 1. Hoc inde ius gentium appellatur, quia eo iure omnes fere gentes utuntur".

41 "Todos los seres humanos nacen libres e iguales en dignidad y derechos y, dotados como están de razón y conciencia, deben comportarse fraternalmente los unos con los otros" (Declaración Universal de los Derechos Humanos, 1948) y su precedente: "Les hommes naissent et demeurent libres et égaux en droits. Les distinctions sociales ne peuvent être fondées que sur l'utilité commune" (Déclaration des droits de l'homme et du citoyen, 1789). Fue Fernando Vázquez de Menchaca el encargado de revitalizar el concepto de libertad natural que terminó imponiéndose en la modernidad. Ver Carpintero, La ley natural, 152ss. El individuo libre y aislado en estado de naturaleza se constituye en referencia teórica desde la cual argumentar en términos jurídicos y políticos. Este modelo antropológico está presente en Grocio y en Pufendorf. 
por conveniencia ("disposiciones útiles para la vida humana" ${ }^{42}$ ) la propiedad común se divide en propiedades particulares en aras a lograr una administración eficiente y pacífica de los bienes. Los tratos mercantiles constituirían el ejemplo paradigmático de asunción de obligaciones a partir del libre consentimiento entre iguales. ${ }^{43}$ Por su parte, la teoría del contrato social expresa el surgimiento de la comunidad política por la libre autodeterminación de individuos que, previamente, se encontrarían aislados en estado de naturaleza. ${ }^{44}$

Actualmente, al negarse la existencia de una ley natural y la consiguiente sociabilidad, sólo el libre consentimiento, directo o delegado en el poder político, se considera origen legítimo del derecho que se identifica con la ley. Por el contrario, el pensamiento jurídico romano y medieval combina necesidad natural y libre consentimiento según las variadas circunstancias que concurren en la determinación de lo justo. Por ello es posible que el derecho de gentes, aun siendo positivo, no surja de un acuerdo explícito entre las naciones, sino tácito como, por ejemplo, expone Vitoria que podría haber sucedido en relación a la división de la propiedad común (véase más adelante) o el surgimiento de la potestad política al margen de cualquier contrato social. ${ }^{45}$ El reconocimiento de dominio a

42 STh I-II, c. 94, a. 5.

43 Decock destaca el lugar central que ocupa el principio de libre consentimiento en el pensamiento escolástico para hacer válido un contrato desde la perspectiva del derecho natural. Se acuerdan contratos para el mutuo beneficio y se entienden como "una promesa mutuamente aceptada que, para las partes, ocupa el lugar de la ley". Elevados a "legisladores privados", los sujetos contrayentes, que disponen de dominio sobre la propia voluntad y los propios bienes, se obligan mutuamente para llevar a cabo determinados cursos de acción, de modo que acuerdan su propia ley, sujeta, no obstante, a limitaciones. Estas son de tipo natural (como la coacción y la ignorancia, vicios de la voluntad que anulan el contrato), de tipo político y formal (como la equidad propia de la justicia conmutativa, la ausencia de fraude, la protección de los intereses de las partes) y de tipo sustantivo y moral (como los contratos de prostitución y de usura que, aunque inmorales, tienen relevancia legal). Es evidente que, desde la libertad y el aislamiento propios del estado de naturaleza, estos "legisladores privados", sus dominios respectivos y los contratos que acuerdan resultan equiparables al legislador público, su jurisdicción y la promulgación de la ley. Ver Wim Decock, Theologians and Contract Law: The Moral Transformations of the Ius Commune (ca. 1500-1650) (Leiden: Nijhoff, 2013).

44 Hobbes identifica el estado de naturaleza con el estado de guerra (Leviathan, cap. 13) en oposición al estado de naturaleza íntegra de la tradición escolástica. En respuesta, Locke reitera la noción clásica: "El estado de naturaleza es gobernado por la ley natural, que obliga a todos; y la razón, que es esta ley, enseña a todos los hombres ...que siendo todos iguales e independientes, ninguno debe dañar a otro en la vida, la salud, la libertad y sus posesiones, porque todos los hombres, siendo hechura de un solo creador omnipotente ...son propiedad de aquél por quien han sido creados ...y puesto que todos hemos sido dotados de las mismas facultades y participamos de una sola y común naturaleza, no es posible suponer entre nosotros ninguna subordinación" (Two Treatises of Goverment, II, II, 12). El fundamento de todo pacto y de toda ley positiva promulgada por los hombres es la ley natural, no lo contrario como afirma el contractualismo positivista de Hobbes para quien el pacto crea la moral y el derecho. Ver Prieto, "La Ley natural".

45 Vitoria analiza la necesidad natural del poder político en la relección De potestate civili de clara inspiración aristotélico-tomista y explícitamente opuesta al contractualismo político. Sin la naturaleza social del hombre no se entienden ni la palabra, ni la sabiduría, ni la justicia, ni la amistad. 
los pueblos americanos no podría haber tenido lugar desde un positivismo jurídico que niega la existencia de una naturaleza desde la que deducir derechos naturales subjetivos. En ese caso, los indios carecerían de derechos en tanto no se llegara a un acuerdo que los creara explícitamente, suponiendo que les fuera reconocida capacidad para firmar tal acuerdo.

Sobre el derecho natural, santo Tomás afirma que le corresponde lo justo por naturaleza, mientras que por acuerdo privado o por convención pública (todo el pueblo consiente o lo ordena el gobernante) surge el derecho positivo, que no puede contravenir al natural. El derecho positivo convierte en justo aquello que, sin oponerse a la ley natural, pasa a constituirse en legalmente justo por la voluntad humana ${ }^{46} \mathrm{La}$ ley escrita contiene el derecho natural, pero no lo instituye, ya que su fuerza de ley deriva de la naturaleza, mientras que sí lo hace en el derecho positivo. ${ }^{47}$ De modo análogo, el derecho divino puede dividirse en dos. En la ley divina hay cosas mandadas o prohibidas por ser naturalmente buenas o malas, pero otras son buenas o malas por ser mandadas o prohibidas. ${ }^{48}$

Por su parte, afirma Francisco de Vitoria que justo natural se dice de aquello que es igual por su propia naturaleza, como devolver lo mismo que se ha recibido en depósito. Justo positivo y humano es lo determinado por un pacto público, y a esto se llama ley, o también por un pacto privado. ${ }^{49}$ El derecho natural también se denomina necesario por no depender de la voluntad humana: para que algo sea necesario basta con que la naturaleza no pueda disponer lo contrario, aunque la autoridad divina pudiera disponer otra cosa. Nada es de derecho natural si no se puede conocer naturalmente. Recuerda Vitoria a santo Tomás al afirmar que son de derecho natural las cosas que pueden ser conocidas

Las sociedades humanas están para que "cada uno sobrelleve las cargas de los demás” y entre ellas la sociedad civil es "una naturalísima comunicación, en sumo grado conveniente a la naturaleza". Las ciudades y las repúblicas ni son invento de los hombres, ni creaciones artificiales, sino algo que procede de la naturaleza misma y por la misma razón existe la potestad. Su origen natural se deriva de resultar imposible que la multitud dicte leyes o dirima pleitos y de que sea necesario confirmar la administración a uno o varios. La libertad evangélica no se opone a la ley natural, de ahí que haya que obedecer a los príncipes legítimos, pues su autoridad proviene de Dios (Rm. 13:1). El estado en que todos eran iguales, nadie mandaba y todo era poseído en común no sirve de justificación para rechazar la necesidad del poder político. De ningún modo puede provenir la potestad de un contrato convenido entre los hombres, pues en las repúblicas "incluso contra la voluntad de todos los ciudadanos" es preciso constituir una potestad para su administración: "el poder público es la autoridad o el derecho de gobernar la república civil".

46 STh II-II, c. 57, a. 2.

47 STh II-II, c. 60, a. 5.

48 STh II-II, c. 57, a. 2 ad 3.

49 Comentario a STh II-II, c. 57, a. 2. 
por todos, salvo obstáculos como una mala costumbre, alguna depravada inclinación o una mala enseñanza o estudio.

Afirma Vitoria que la justicia atiende a lo que es debido y lo debido busca preservar una igualdad que, para serlo, prescinde de la condición de las partes. ${ }^{50}$ Por ejemplo, es indiferente que el que compra sea rico o pobre con tal de que dé lo equivalente. ${ }^{51}$ Propiamente, el derecho es lo justo (ius) y lo justo es el objeto de la justicia (iustitia): como consecuencia de que opera una acción justa resulta algo que es justo. El derecho no es la ley. Ésta última es más bien una regla a la que ajustarse, es cierta razón o causa del derecho. Cuando los juristas afirman que la justicia es "una firme y constante voluntad de dar a cada uno su derecho"52 resulta claro que no se está tomando el derecho como si fuera lo mismo que la ley.

El derecho natural por su naturaleza es medido en relación a otro. Se puede entender en sí mismo porque afirma cierta igualdad y justicia como devolver lo prestado o no hagas a otro lo que no quieras que te hagan a ti. Por el contrario, el derecho de gentes se entiende como algo que es adecuado a otro en orden a otra $\cos a^{53}$, como la división de las posesiones que no se refiere directamente a la igualdad y la justicia sino que se ordena a la paz entre los hombres ${ }^{54} \mathrm{El}$ derecho de gentes conlleva la equidad en relación a alguna otra cosa; no es equitativo por sí mismo, sino por un estatuto humano fijado racionalmente. Vitoria corrobora la clasificación de santo Tomás: el derecho natural es un bien por sí mismo, mientras que el de gentes no tiene en sí equidad, sino que está sancionado por un consenso de los hombres, es por tanto derecho positivo. Por ello los teólogos mencionan correctamente, como ejemplos de derecho de gentes, la propiedad de los bienes, la servidumbre, las manumisiones o la conservación del reino.

50 Comentario a STh II-II, c. 57, a. 1.

51 No podemos entrar en este trabajo en las implicaciones que los conceptos de ley natural y de lo justo como lo igual tienen sobre la economía. A este respecto, pueden consultarse: José Luis Cendejas, "Economics, chrematistics, oikos and polis in Aristotle and St. Thomas Aquinas", The Journal of Philosophical Economics 10, n. 2 (2017): 5-46 y "Justicia, mercado y precio en Francisco de Vitoria", Revista Empresa y Humanismo 21, n. 2 (2018): 9-38.

52 Definición basada en Ulpiano: "Iustitia est constans et perpetua voluntas ius suum cuique tribuendi" (Dig. 1.1.10pr) y "Iuris praecepta sunt haec: honeste vivere, alterum non laedere, suum cuique tribuere" (Dig. 1.1.10.1).

53 Cruz aclara que la necesidad constitutiva es propia del derecho natural mientras que la necesidad normativa consecutiva pertenece al derecho de gentes. Ambos gozan de validez universal necesaria. Ver Juan Cruz, "La presencia de la ley natural en el ius gentium según Francisco de Vitoria", en Ley natural y niveles antropológicos: Lecturas sobre Santo Tomás, ed. por J. Cruz (Pamplona: Universidad de Navarra, 2007).

54 Comentario a STh II-II, c. 57, a. 3. 
El derecho de gentes no se deduce necesariamente del natural, pues entonces también sería derecho natural. Sin embargo, resulta casi necesario para la conservación del natural. Por ejemplo, podría subsistir un mundo sin propiedad particular, como se rige en las órdenes religiosas, pero habría discordias y guerras. Que el derecho de gentes no sea natural ni necesario, sino positivo, no implica que pueda abolirse igual que el resto del derecho positivo: cuando por acuerdo de todo el orbe se admite algo, para su derogación sería preciso idéntico acuerdo, pero resulta imposible que todo el orbe se ponga de acuerdo para la abolición del derecho de gentes. ${ }^{55}$ Afirma Vitoria en De Potestate Civili que, del mismo modo que las leyes obligan al que las promulga, sea el rey, los senadoconsultos bajo el régimen del principado aristocrático o los plebiscitos en el régimen popular, el derecho de gentes obliga no solo por convenio o pacto entre los hombres, sino por tener verdadera fuerza de ley. De modo análogo, todo el orbe (totus orbis), que en cierta manera es una república, tiene el poder de dar leyes justas y convenientes que son el derecho de gentes. Así que pecan los que violan los derechos de gentes, sean de paz, sobre la guerra o la inviolabilidad de los legados. El derecho de gentes está dado por la autoridad de todo el orbe y obliga por ello a todas las naciones.

El modo en que el derecho de gentes se determina a partir del natural queda patente en la relección De indis. Ésta tiene por objeto resolver la cuestión sobre el dominio, de propiedad y de jurisdicción, de los indios; esto es, si eran "dueños de sus cosas privadas y de sus haciendas, y si había entre ellos verdaderos príncipes y señores de otros indios". Si fueran siervos por naturaleza, siguiendo a Aristóteles, carecerían de dicho dominio, pero a esto se opone el hecho de que "estaban en pacífica posesión de sus cosas, pública y privadamente". En este caso, ni el pecado mortal en que pudieran estar, ni el hecho de ser infieles o "dementes o insensatos" impedirían el dominio civil y el natural. Es así porque el dominio se funda en el hecho de ser el hombre imagen de Dios, en sus potencias racionales, y esto no se pierde por el pecado mortal ni tampoco por la infidelidad o la herejía. De los bárbaros no puede decirse que sean "amentes" sino que "guardan un orden en sus cosas", lo que requiere uso de razón. No obstante tener verdadero dominio, quien es más sabio ha recibido de la naturaleza facultades para mandar y gobernar -a esto se refiere Aristóteles, según Vitoria, cuando justifica la servidumbre natural; como se ha señalado anteriormente, la esclavitud no se considera de derecho natural- de donde sí podría nacer algún derecho para someter a los indios. 
No siendo la ausencia de dominio un título legítimo por el cual los bárbaros del Nuevo Mundo quedaron bajo poder de los españoles (tampoco otros como la potestad del emperador o del papa, el derecho de descubrimiento, la resistencia a recibir la fe de Cristo, sus pecados mortales, la elección voluntaria o la donación de Dios), Vitoria pasa a considerar otros títulos de origen natural. El primero puede denominarse de la sociedad y comunicación natural que ha de ejercerse sin perjuicio de los naturales. En el principio del mundo las cosas eran comunes, por lo que aún resulta lícito dirigirse a todas las regiones y recorrerlas, ya que la división de las tierras no ha abolido esta libertad. La peregrinación de los españoles no injuria ni daña, por lo que es lícita. También lo es el hecho de establecerse en las nuevas tierras, ya que el destierro es pena capital y ello se aplica también a los huéspedes. Los huéspedes deben ser recibidos en virtud de la amistad natural entre los hombres que Cristo eleva a mandato ("era peregrino y no me hospedasteis" ${ }^{56}$ ). Según las Institutiones, por derecho natural son comunes las aguas corrientes y el mar, los ríos y los puertos en los que las naves pueden atracar. ${ }^{57}$ Dado que los indios admiten a otros, sería injuria no hacerlo con los españoles. Si se prohibiera todo esto sin causa, no lo sería por ley divina ni natural, sino por ley humana que no tendría fuerza de ley por oponerse a la natural. Si los españoles fueran súbditos de los bárbaros, esto se les podría prohibir a los españoles, pero como no lo son, se les ha de tratar debidamente. Los españoles son prójimos de los bárbaros y como tales están obligados a amarlos.

Es lícito el comercio de los españoles con los bárbaros sin perjuicio de su patria vendiéndoles aquello de lo que carecen, y extrayendo oro y plata u otras cosas de las que tienen abundancia. Los príncipes respectivos no pueden impedirlo. Es así porque parece de derecho de gentes que a los transeúntes extranjeros se les deje comerciar sin daño de los ciudadanos. También es lícito por derecho divino, pues la ley divina incluye la natural a la que pertenece el derecho de gentes. Sin una causa, los príncipes no pueden impedir a los españoles comerciar si puede hacerse sin daño propio, dado que no se ha de querer para los demás lo que no se quiere para uno mismo. Va contra el derecho natural que el hombre se aparte del hombre sin causa, pues, como afirma el cómico, "el hombre no es un lobo para el hombre, sino hombre"s8.

56 Mt. 25:43.

57 Por derecho natural hay cosas comunes a todos (res communes omnium) que, por su naturaleza, no son apropiables con exclusividad y se excluyen por ello del tráfico jurídico, así el aire, el agua corriente, el mar y sus riberas (Dig. 1.8.2), aunque podrían ser res publicae (Dig. 43.8.2.9, 50.16.112).

58 Plauto, Asinaria, v. 495. 
No es lícito que, si hay cosas comunes entre los bárbaros que son comunes a los ciudadanos y a los huéspedes, aquellos prohíban a los españoles la comunicación y participación de esas cosas mientras no sean gravosas a los naturales del país. Además de la licitud de peregrinar y comerciar, es lícito por derecho de gentes que las cosas que carecen de dueño (res nullius) pasen a ser del que las ocupa ${ }^{59}$, así el oro, las perlas o los peces. Y es que el derecho de gentes tiene fuerza de derecho por derivarse suficientemente del natural y, cuando no es así, basta el consentimiento de la mayor parte del orbe, sobre todo si es en favor del bien común. Por ello los legados son intocables, los mares son comunes, los cautivos de guerra devienen esclavos y los huéspedes no son expulsados. ${ }^{60}$

\section{NATURALEZA CAÍDA, DOMINIO Y PROPIEDAD}

Conforme al derecho natural y en el estado de naturaleza íntegra, rige la comunidad de bienes, pues, como afirma Vitoria, es equitativa en sí misma. Esta es la forma que adopta el dominio sobre las cosas en dicho estado. Aunque se considera específica del derecho natural, el derecho de gentes, que es positivo, mantiene la propiedad común en determinadas circunstancias (estado de necesidad, bienes naturalmente no apropiables), pues con la Caída no queda derogada, sino que la división de las posesiones pasa entonces a ser lo más adecuado por razones de diverso tipo (convivencia, eficiencia, etc.) sin resultar en ningún caso preceptiva. Con ciertos matices, más de expresión que sustantivos, ésta es la postura generalmente aceptada por el pensamiento escolástico.

Por incluir el derecho natural, el derecho divino también prescribe la comunidad de bienes. Así, el Decreto de Graciano afirma la comunidad de bienes por derecho divino, mientras que por derecho humano "esto es mío, aquello de otro"61. La comunidad de bienes fue observada por los primeros cristianos, citando: "La multitud de los creyentes tenía un solo corazón y una sola alma. Nadie consideraba sus bienes como propios, sino que todo era común entre ellos"62. Y recuerda también el Decreto la comunidad ideal descrita en la República de Platón donde "se desconoce el afecto de los propios".

59 Dig. 41.1.3pr.

60 El resto de la relección se refiere a las causas justas de guerra, luego ampliadas en De iure belli, y a otros títulos legítimos por los que los indios vinieron a poder de los españoles.

61 Dist. VIII, pars 1, c. 1, tomado de san Agustín.

62 Hch. 4:32. 
Para Alejandro de Hales ${ }^{63}$ la ley natural prescribe de distinto modo distintas cosas: i) por debido, la comunidad de bienes en caso de necesidad; ii) por bueno, que "en estado de naturaleza bien ordenada ... todas las cosas fuesen comunes, pero en estado de naturaleza corrompida establece que es bueno que algunas cosas sean propias; en otro caso los buenos sufrirían necesidad y no se sostendría la sociedad humana, porque los malos se apoderarían de todo"64; y iii) por justo, que algunas cosas sean propias en el estado posterior a la Caída, otras sin dueño sean apropiables (aves, peces) y otras no lo sean (el aire, el mar, las costas). Es decir, aunque no debido, sí es bueno -conveniente- que haya cosas propias en el estado de naturaleza caída y también justo que ciertas cosas permanezcan como comunes.

San Alberto Magno señala que el derecho natural determina que todas las cosas sean comunes y que algo sea propio condicionado al estado de naturaleza íntegra o caída. En el estado "en que no hay rapiña ni usurpación" nada era propio, mientras que "creciendo la malicia y la rapiña y el rencor, se sirve la naturaleza de otro principio: debe ser reivindicado lo propio para la provisión de los de uno y de los pobres". Aunque en tiempo de necesidad se han de comunicar los bienes. ${ }^{65}$

San Buenaventura distingue tres sentidos en el dominio (potestas dominandi vel praesidendi) que se corresponden de distinto modo con los estados de naturaleza íntegra, naturaleza caída y naturaleza glorificada: i) en sentido amplísimo, el dominio se refiere al uso de todas las cosas por el hombre según arbitrio y deseo. Esta forma de dominio es común a los tres estados, aunque más excelente en el estado de naturaleza íntegra que en el de naturaleza caída; ii) en sentido general, la potestad de dominio se refiere a la excelencia de la autoridad sobre el que es capaz de razón y preceptos, por ejemplo, del marido sobre la mujer o del padre sobre el hijo. Este segundo sentido corresponde a los estados de naturaleza íntegra y caída ya que esta potestad no persistirá en la gloria; y iii) en sentido propio, la potestad de dominio restringe la libertad y significa el poder de obligar a los súbditos y a los siervos. En este sentido el dominio existe solo en el estado de naturaleza caída pues la servidumbre que le corresponde es la pena por el pecado. Es preciso diferenciar los preceptos que son dictamen de la naturaleza íntegra de los que lo son de la naturaleza caída. Así, por ejemplo, que

63 Zorroza amplía sustancialmente lo indicado aquí en relación a Alejandro de Hales y San Alberto Magno. Ver M. Idoya Zorroza, "La relación del ser humano con el mundo, en forma de dominio, según Alejandro de Hales", Cauriensia 11 (2016): 315-346, y "La definición del dominio según Alberto Magno", Cauriensia 8 (2013): 411-432.

64 Summa Theologica, II, inq. 2, q. 4, en Restituto Sierra, El pensamiento social y económico de la Escolástica desde sus origenes al comienzo del Catolicismo social (Madrid: CSIC, 1975), 306.

65 Suma de criaturas. Tratado 'De bono', en Sierra, El pensamiento social, 327. 
haya cosas propias lo dicta la naturaleza en el estado de caída para evitar riñas y pleitos. Que el hombre sea siervo de Dios vale para todo estado, pero que "el hombre sea igualado al hombre" solo vale según la condición primera. Según el estado de naturaleza corrompida, el hombre se somete al hombre para que los malos sean contenidos y los buenos defendidos. En otro caso no se podría vivir en sociedad. ${ }^{66}$

Respecto a la comunidad de bienes, afirma San Buenaventura, se dicta en el estado de naturaleza inocente, pero no en el de naturaleza caída. Conforme a la concepción franciscana sobre la propiedad, según el grado de renuncia al dominio, la pobreza evangélica puede tener dos formas: i) cuando se renuncia al dominio de lo propio y uno se sustenta de lo que es común a un colegio; y ii) cuando se prescinde también de esto último y uno pasa a sustentarse de lo ofrecido piadosamente por otros, ${ }^{67}$ lo que constituye su ápice de perfección.

Para santo Tomás, las cosas exteriores, en cuanto a su naturaleza, no están sometidas a la potestad humana, sino a la divina a la que obedecen todos los seres. Pero en cuanto a su uso, ${ }^{68}$ el hombre puede usar de ellas dado que los seres imperfectos existen por los más perfectos, siendo su dominio, por tanto, natural. El dominio le compete al hombre debido a su razón ${ }^{69}$ en la que reside la imagen de Dios, de ahí que la posesión de las cosas exteriores sea natural al hombre. ${ }^{70}$ Respecto a la comunidad de bienes, afirma el Aquinate que en el estado de inocencia estaban armonizadas las voluntades individuales de modo que cada

66 Comentarios sobre las Sentencias, libro 2, dist. 44, a. 2, c. 2; en Sierra, El pensamiento social, p. 331, p. 332 .

67 Apología de los pobres, cap. 4, n. 4; en Sierra, El pensamiento social..., p. 339. Los franciscanos optaron por un voto de pobreza más exigente que el resto de las órdenes, por el cual carecían de bienes propios tanto individual como corporativamente, lo que había sido aceptado por el papa Nicolás III (decretal Exiit qui seminat de 1279), de modo que la orden carecía de todo ius domini y disfrutaba sólo del uso de hecho: la propiedad de los bienes permanecía en manos de los benefactores o del papa. Juan XXII decidió acabar con este artificio jurídico pues resultaba evidente que la orden mantenía, de hecho, el ius fruendi y el ius utendi; de otro modo, los franciscanos estarían actuando contra derecho. En respuesta al papado, Ockham afirmó que la orden carecía de toda potestas, lo que incluía el derecho a usar, pues no podía reclamar nada judicialmente. Los franciscanos se encontrarían así en una situación análoga a la que existía antes de la división de las cosas, de modo que podrían hacer uso de hecho sin tener dominio. Ver Carlos A. Casanova, "Guillermo de Ockham y el origen de la concepción nominalista de los derechos subjetivos", Cauriensia 11 (2016): 113-140. También, en el mismo número, los trabajos de G. Castillo y M. Lázaro sobre la pobreza evangélica según San Buenaventura.

68 Idea análoga en Pedro Lombardo pero referida a la relación señorial: “...los bienes de los señores se dice son de los siervos, no por dominio, sino en cuanto a su uso" (Sentencias, libro 2, dist. 1, n. 8; en Sierra, El pensamiento social, 295). O en San Alberto Magno, sobre el rico: "lo que ha sido dado a todos para uso común lo posee como administrador" (Comentarios en el Evangelio de San Mateo, cap. 6, vers. 24; en Sierra, El pensamiento social, p. 315).

69 STh I, c. 96 , a. 1 у а. 2.

70 STh II-II, c. 66, a. 1. 
uno tomaba del bien común lo que le correspondía sin peligro de discordia, lo que aún se ve entre hombres rectos. Sin embargo, en nuestro estado, la comunidad de posesión es origen de discordias y es preciso dividir las posesiones, lo que también afirma el Filósofo. ${ }^{71}$

A pesar de regir la propiedad común en el estado de inocencia, para santo Tomás, los hombres no eran todos iguales, sino que había diferencias entre ellos, pues el orden consiste en una disposición en que lo igual y lo desigual ocupan su lugar propio. ${ }^{72}$ Además de la disparidad propia de la diferencia de sexos, estaría la de edad, así como la de justicia y ciencia, debido a que el obrar libre del hombre crearía diferencias en ambas. También habría diferencias en los cuerpos. En cualquier caso, ninguna de estas diferencias implicaría defecto ni pecado en el alma ni en el cuerpo. ${ }^{73}$

También es posible que en el estado de inocencia hubiera dominio de unos hombres sobre otros, ya que también hay dominaciones entre los ángeles y el hombre no es más digno que éstos. El dominio tiene doble acepción. Por la primera es lo opuesto a la servidumbre: domina quien tiene siervo. Este dominio no se daba en el estado de inocencia pues implica la aflicción de los sometidos que han de dar a otro lo que es propio. La segunda acepción de dominio se refiere a cualquier modo de sujeción: domina quien tiene el gobierno o dirección de personas libres. ${ }^{74}$ Este dominio está presente en el estado de caída y es posible en el de inocencia. ${ }^{75} \mathrm{El}$ dominio libre alinea el bien del dominado al bien común, que es la ordenación de muchas cosas a una sola para lo cual es preciso que uno dirija. Adicionalmente, este dominio pone al servicio de los demás la superioridad de ciencia y de justicia de que algunos gozan. En este sentido "el don que cada uno ha recibido, póngalo al servicio de los otros" $"$. y conforme a san

71 STh I, c. 98, a. 1 ad 3.

72 San Agustín, De Civitate Dei, XIX, cap. 13.

73 STh I, c. 96, a. 3.

74 En Super Sent. (libro 1, d. 2 q. 1 a. 5 expos) Tomás de Aquino recoge las acepciones de Boecio (De Trin., 1) por la cual el dominio es el poder de obligar a los súbditos; y de Dionisio (De div. nom., 12) quien afirma que el dominio no es sólo la excelencia sobre los inferiores, sino también la total y perfecta posesión de las cosas buenas y bellas; para que alguien sea señor, se exigen las riquezas y el poder. Como vemos a continuación, para el Aquinate, mediante la relación de dominio, el dominus pone al servicio del dominado (carente) aquello que le hace precisamente señor (ciencia, justicia, poder, riquezas...).

75 En los Comentarios sobre las Sentencias (libro 2, dist. 44, c. 1 a. 3; en Sierra, El pensamiento social, 398-399), el Aquinate reitera la idea. El dominio como gobierno existía en el estado de inocencia, si bien limitado a su función de dirigir lo que se debía hacer o saber, en tanto los gobernantes tuvieran mayores dones de sabiduría o de inteligencia. La segunda función del gobierno, junto con la anterior, está presente en el estado de Caída, a saber, castigar a los malos e impulsar coactivamente actos de virtud.

761 Pe. 4:10. 
Agustín 77 "los justos no mandan por el deseo de mandar, sino por el deber de aconsejar. Así es el orden natural y así creó Dios al hombre"78.

El dominio que compete a Dios y el que compete al hombre son distintos. Dios tiene dominio principal y plenario sobre todas las criaturas. El hombre participa de una semejanza del dominio divino al tener poder sobre otro hombre o sobre otra criatura. ${ }^{79}$ Es de acuerdo con la ley natural que los seres superiores muevan a los inferiores a causa de la virtud natural más excelente que Dios les ha conferido. De donde también entre los hombres los superiores han de gobernar a los inferiores ${ }^{80} \mathrm{El}$ súbdito está exento de obediencia por razón de mandato de orden superior, por ejemplo, si Dios lo manda, y, en segundo lugar, si lo que le manda el superior está fuera del límite de su autoridad. Por ejemplo, no se está obligado a obedecer en lo referido a los actos interiores de la voluntad. ${ }^{81} \mathrm{La}$ obediencia se refiere a los actos externos y corporales dentro del ámbito de su superioridad (el ejército, el servicio doméstico, los hijos respecto de los padres) y tampoco incluyen todo acto, pues se excluyen los actos pertinentes a la naturaleza corporal, como el sustento, la generación de la prole -por ejemplo en lo que concierne a contraer matrimonio-y similares, en los que todos los hombres son iguales por naturaleza. En estos aspectos la obediencia es debida sólo a Dios. ${ }^{82}$

La división de la propiedad no destruye la justicia propia de la comunidad de bienes, sino que supone una adaptación necesaria, por ello justa, al estado de naturaleza caída. Afirma santo Tomás que no hay razón para que un terreno pertenezca a una persona con preferencia sobre otra, pero sí que sea de uno y no de otros en atención a su cultivo y uso pacífico, recordando el Aquinate a Aristóteles. ${ }^{83}$ Así que es lícito que el hombre posea cosas propias ${ }^{84}$ debido a tres razones: i) cada uno es más solícito en lo propio que en lo común pues cada cual, huyendo del trabajo, termina delegando en otros el cuidado del bien común; ii) se administra de modo más ordenado lo propio que si uno tiene que ocuparse de todo indistintamente reinando entonces la confusión; y iii) se mantiene el estado

77 De Civitate Dei, XIX, cap. 14.

78 STh I, c. 96, a. 4.

79 STh II-II, c. 103, a. 3. Véase también Brufau, "La noción analógica del 'dominium"”.

80 STh II-II, c. 104, a. 1.

81 Cita santo Tomás a Séneca en relación a la esclavitud: "Se equivoca el que cree que la servidumbre afecta al hombre entero. Su parte más noble está exenta. Los cuerpos están sometidos y entregados como esclavos a sus dueños; pero el alma es dueña de sí misma" (De Beneficiis, III, c. 20). Es oportuno recordar también a Calderón: "Al rey la hacienda y la vida se ha de dar, pero el honor es patrimonio del alma, y el alma sólo es de Dios" (El alcalde de Zalamea).

82 STh II-II, c. 104, a. 5.

83 STh II-II, c. 57, a. 3.

84 STh II-II, c. 66, a. 2. 
de paz entre los hombres si cada uno está contento con lo suyo -en aquello que es común suelen suscitarse contiendas con más frecuencia-. Las dos primeras son razones de eficiencia - dicho en términos actuales- mientras que la tercera, de mayor peso en el pensamiento escolástico, es por razón de la paz.

No obstante, la división de la propiedad no deroga la comunidad de bienes. De ella se deriva precisamente lo que, a día de hoy, la Doctrina Social de la Iglesia denomina destino universal de los bienes: el uso de los bienes no implica que se tengan las cosas exteriores como propias, sino como comunes, lo que, siguiendo al Aquinate, debe interpretarse como que se dé fácilmente participación de éstas en las necesidades de los otros. De ahí que, si alguien se apropia de algo que era común en el comienzo, no debe privar de su uso a los demás. ${ }^{85}$ El hecho de que la división de las posesiones no sea de derecho natural, sino positivo, no implica que el derecho natural se oponga a la propiedad particular. La propiedad es un desarrollo del derecho natural hecho por la razón humana por conveniencia debido a las tres las razones expuestas. ${ }^{86}$

Por su parte, afirma Vitoria que la vigencia del derecho natural se manifiesta en el hecho de que, por derecho de gentes, las cosas sin dueño, como tesoros y minas, sean del primer ocupante o del que las encuentra. Sólo si esto no conviene a la república, pueden dividirse entre los que forman parte de ella. ${ }^{87}$ Vitoria confirma la licitud de que los cristianos tengan bienes propios ${ }^{88}$ De otro modo no se entendería la obligación de la limosna, pues de lo que es común no puede darse limosna. La comunidad de la que se habla en los Hechos de los Apóstoles, además de voluntaria, fue de duración desconocida, afirma Vitoria. El hecho de que se hicieran colectas para los pobres muestra que en ella había también cosas que no eran comunes. La comunidad de bienes requiere muchas cosas que no suelen hallarse en la sociedad: modestia, concordia, debida sujeción, justa distribución, las cuales a duras penas se dan entre los religiosos. Bajo un régimen de comunidad de bienes, el avaro y el ladrón se llevarían más cosas que el buen varón.

85 STh II-II, c. 66, a. 2 ad 2.

86 STh II-II, c. 66, a. 2 ad 1.

87 Comentario a STh II-II, c. 66, a. 1.

88 Comentario a STh II-II, c. 66, a. 2. 


\section{EL DOMINIO COMO DERECHO SEGÚN FRANCISCO DE VITORIA}

Francisco de Vitoria analiza el dominio al comentar la c. 62 de la Secunda Secundae relativa a la restitución, ${ }^{89}$ a pesar de que santo Tomás no trata el dominio en esta cuestión. El concepto de ius como derecho subjetivo, equivalente al concepto de dominio, difiere del presentado más arriba al referirnos a su comentario a la c. 57, donde ius se entiende como la cosa justa. Afirma Vitoria que toda restitución se funda en el dominio. El dominio puede entenderse de tres modos: i) indica cierta eminencia o superioridad y trae consigo potestad para obligar sobre los súbditos. En este sentido ius y dominium no coinciden, pues ius es más amplio; por ejemplo, la esposa o el hijo tienen algún derecho (ius) sobre el marido o los padres, pero no tienen dominium; ii) tal como se emplea en el Corpus Iuris Civilis como equivalente a propiedad distinguiéndose del uso, ${ }^{90}$ el usufructo o la posesión. Usuario y usufructuario tienen algún derecho pero no son dueños (domini) de la cosa; y iii) para indicar la facultad de usar una cosa de acuerdo con los derechos o las leyes razonablemente instituidas. ${ }^{91}$ Definido en este sentido coinciden dominio y derecho. Aunque los jurisconsultos no acepten este sentido, afirma Vitoria, en términos de moral y de restitución, es correcto, pues si se le quita a alguien la facultad de usar algo sobre lo que tiene derecho, aunque no sea el dueño -dominio en sentido amplio-, se le debe restituir dicha facultad.

Dios es dueño de todas las criaturas, continúa Vitoria, y de todo el orbe, lo que es evidente por derecho natural: Él las creó y, al no tener superior al que le pertenecieran, es su dueño. Dios no puede carecer del dominio sobre las cosas ni privarse de él, ni nosotros no ser de él. Así que todo derecho y dominio que se halla en las criaturas es dado por Dios: "por mi reinan los reyes" 92 y "no hay

89 En Sierra, El pensamiento social, 588-600, que parte de la edición de Beltrán de Heredia, 1932, vol. 2.

90 Domingo de Soto, respecto al dominio sobre las cosas, mantiene la división de Vitoria lo que le sirve para aclarar la posición de los franciscanos, que rechazaban ser dueños de algo. Ver M. Idoya Zorroza y Manuel Lázaro, "Uso, dominio y propiedad en la Escuela Franciscana". Cauriensia 11 (2016): 23-51.

91 Siguiendo a Summenhart (De contractibus, q. I, tr. I). Summenhart, a quien Vitoria atribuye la definición, está siguiendo a Gerson. Guzmán Brito ("La doctrina del derecho-facultad...") indica que la definición de Vitoria de derecho como facultad sintetiza en una las definiciones de Gerson de ius y de dominium: "Ius est potestas vel facultas propinqua conveniens alicui secundum dictamen rectae rationis", "Dominium autem est potestas vel facultas propinqua assumendi res alias in sui facultate vel usum licitum secundum iura vel leges rationabiliter institutas". De decir, como Gerson, "conforme a la recta razón" a "conforme a las leyes" hay una diferencia fundamental desde una concepción tomista del derecho.

$92 \operatorname{Pr} .8: 15$. 
potestad sino de Dios" ${ }^{\text {93 }}$. El dominio que le competía cuando solo Él existía no lo comunicó a ninguna criatura irracional, ${ }^{94}$ sino que comunicó a todos los hombres dominio y derecho sobre todos los bienes creados y todas las criaturas: "todo lo pusiste bajo sus pies" los hombres, pues Dios y la naturaleza no hacen nada en vano. Todas las cosas se encuentran ordenadas unas a otras y las más imperfectas son por las más perfectas; el hombre es el más perfecto de todos los seres; luego todos los otros seres están ordenados a él.

El dominio del hombre de usar de las cosas le viene por derecho natural que es parte del derecho divino, junto con el derecho positivo divino-, pues no hay pueblo (gens) que no considere lícito que el hombre use de las cosas. Es dueño porque puede usar de todas las criaturas del modo en que conviene a cada una con el fin de conservar su ser. En el estado de naturaleza íntegra, la comunidad humana y todo hombre (a diferencia de las comunidades, como los monasterios, en que sus miembros no son dueños) tenían dominio sobre todas las cosas. Por el pecado no se perdió este dominio, pues debido a él no se pierden los dones naturales. Por el pecado se perdió el paraíso, pero no las otras cosas. La división de las cosas no se ha hecho por el derecho natural, pues éste nunca cambia, ni tampoco consta que sea por derecho divino positivo. Sino que, como afirma san Agustín: "suprime las leyes de los emperadores y ¿quién se atreverá a decir, esta finca es mía?" por derecho divino ni natural. La división y apropiación de las cosas se ha hecho por derecho humano.

El dominio ha sido concedido por Dios al hombre por derecho natural y ni Él puede derogarlo, como así lo afirma Escoto, para quien la posesión común de las cosas ha sido derogada, afirma Vitoria. Por el contrario, Summenhart arguye que la ley natural permanece inmóvil e inmutable y que ésta nunca ordenó que se hiciera la división de las cosas. La ley puede ser preceptiva, consultiva o permisiva. La ley natural, en lo que concierne a la comunidad de bienes, concedía que en el estado de inocencia todo fuera común, pero no obligaba. Pero, dado que el hombre era dueño de todo por derecho natural, por autoridad humana y sin necesidad de derogar la propiedad común, pudo hacerse la división y apropiación particular de las cosas.

\footnotetext{
93 Rm. 13:1.

94 De ahí que éstas, aun teniendo entidad, no tengan derecho como así lo afirmaba Gerson.

95 Sal. 8:7.

96 Gn. 1:26-28.

97 Tratado sobre el Evangelio de San Juan, trat. VI, 25.
} 
El hecho de que todos los hombres fueran iguales no era óbice para que pudiera hacerse esa división: es verosímil que primero Adán y luego Noé procedieran así. Pero también pudo hacerse por acuerdo entre los hombres mientras lo aceptara la mayoría, pues para la paz, al tratarse de la utilidad común, es necesario que prevalezca la sentencia de la mayoría y esto es de derecho natural. La división de la propiedad también pudo hacerse sin acuerdo formal pero sí virtual conforme cada cual ocupaba tierras y los demás lo aceptaban. Este consenso basta para el derecho de gentes, afirma Vitoria. Del mismo modo se llegó a fijar la inviolabilidad de los legados, expresando un consenso más con hechos que con palabras.

Hecha la división, de las cosas no divididas, como fieras, aves o peces, cualquiera puede apropiarse si nadie lo ha hecho ya ${ }^{98}$, así como navegar por mares y ríos (recuérdese De Indis). Los dominios, en caso de extrema necesidad, son transitorios. Pero los dominios permanentes se transmiten sólo por voluntad del dueño, por ejemplo, por donación o por conmutación, o por voluntad del príncipe, lo que incluye a Dios. De donde se deduce que los cristianos no pueden ocupar las tierras de los infieles si éstos son verdaderos dueños. En estado de derecho natural, sin ley humana en sentido contrario, el dueño puede transmitir a voluntad el dominio y quien lo recibe es verdadero dueño. El segundo título del verdadero dominio es la autoridad del príncipe. Sucede que el hombre en cuanto a su persona, cuerpo y bienes, es más de la república que de sí mismo, por lo que, por justa causa, ésta puede disponer de sus bienes, lo que incluye transferir el dominio a otra persona. Esto sucede porque el poder viene de Dios y Él puede transferir en contra de la voluntad de su dueño, luego también el príncipe puede hacerlo, así como por el hecho de que el príncipe ha sido elegido y ha recibido consentimiento del pueblo, por lo que puede disponer de los bienes particulares.

\section{CONCLUSIONES}

La teoría de los derechos naturales subjetivos de Francisco de Vitoria surge de la confluencia de dos tradiciones distintas en torno al concepto de derecho. De un lado, el realismo tomista que adopta la concepción romana y romanista del derecho entendido como determinación de la cosa justa. Del otro, la nominalista que va a albergar y potenciar en su seno una concepción subjetivista del derecho. Como afirma Guzmán Brito, ${ }^{99}$ Vitoria procedió a tecnificar para el

98 Dig. 41.1.1.1.

99 Guzmán Brito, El derecho como facultad, p. 82. 
ámbito jurídico un concepto filosófico-teológico que el nominalismo traía consigo, aunque el derecho entendido como potestas vel facultas no es una invención nominalista, ya que, siguiendo a Tierney, el derecho canónico medieval abundaba en derechos subjetivos. Si bien, tanto Ockham, con motivo de la polémica sobre la pobreza evangélica, como diversos teólogos y filósofos influidos por el nominalismo iban a ser los encargados de desarrollar toda la potencialidad política y jurídica a que se prestaba el subjetivismo jurídico. Baste citar los nombres de Suárez, Grocio, Locke, Hobbes o Pufendorf, cuyas doctrinas marcan además una trayectoria de secularización creciente del derecho natural.

El derecho subjetivo procede a invertir el orden de determinación de lo justo que comienza por un sujeto, previamente dignificado, y finaliza en la cosa objeto de derecho. La atribución de un derecho subjetivo sin haber determinado previamente la cosa justa puede llevar a no considerar debidamente la existencia de una contraparte afectada por dicha atribución. Este hecho ha favorecido sobremanera la adopción del subjetivismo jurídico por parte de doctrinas utópicas para las que el derecho -la legislación- es un instrumento de transformación social. De ningún modo el análisis de Vitoria cae en la irrealidad utópica, pues, además de tener en cuenta los justos títulos (derechos) alegados por las partes en litigio (por ejemplo, los indios y la Corona española), deduce tales derechos desde un firme fundamento antropológico basado en la ley natural. Por este motivo, la atribución de derechos en Vitoria no precisa de actos explícitos de promulgación, sino que basta reconocer en el otro a un hombre que es imago Dei.

La determinación del derecho natural a través del de gentes tampoco reviste en Vitoria el carácter de voluntarista que adquirirá después bajo perspectivas contractualistas. Vitoria mantiene una concepción orgánica de la sociedad basada en la integración de las dos comunidades naturales, familiar y política, las cuales se extienden a una tercera, también natural, que engloba todo el orbe y a la que cabe atribuir un bien común universal. En el seno de esta comunidad y como consecuencia de la natural sociabilidad humana, se reconoce, no se acuerda, como derecho de gentes la libre comunicación de personas y bienes, así como el dominio que tienen los pueblos para gobernarse y administrar sus bienes.

El molde tomista subyacente en lo natural de los derechos naturales subjetivos de Vitoria está también presente en otros autores de la Escuela de Salamanca. Sin embargo, la mayor coherencia teórica de una concepción subjetivista del derecho con el voluntarismo de los nominalistas hacía inevitable que la teoría de los derechos subjetivos acabara encontrando un mejor acomodo en su modelo teológico y antropológico. El mito del estado de naturaleza será objeto 
de diversos desarrollos por parte del voluntarismo político y jurídico en tanto referente de proyectos utópicos. Aunque presente en santo Tomás como hemos comprobado, el estado de naturaleza que el Aquinate esboza se inserta plenamente en su realismo antropológico (existencia de diferencias naturales entre las personas así como de vínculos familiares y políticos), lo que irá desapareciendo progresivamente en otras ideaciones que de dicho estado harán autores posteriores. Tanto para el Aquinate como para Vitoria el estado de naturaleza íntegra se diferencia del estado de caída exclusivamente por la ausencia del pecado y sus consecuencias. En versiones posteriores de este estado, individuos perfectamente aislados, portadores de una irrestricta libertad natural, llegarán a acuerdos mutuamente ventajosos, políticos o mercantiles, donde se crearán y negociarán derechos en aras, exclusivamente, de una plena felicidad intramundana.

\section{REFERENCIAS BIBLIOGRÁFICAS}

Abellán, José Luis. La edad de Oro (siglo XVI). Tomo 2 de Historia crítica del pensamiento español. Madrid: Espasa Calpe, 1979.

Aquino, Tomás de. Suma de Teología. Madrid: Biblioteca de Autores Cristianos, 2001

Aristóteles. Ética nicomáquea. Traducido por J. Pallí Bonet. Madrid: Gredos, 1985.

—. Política. Traducido por M. García Valdés. Madrid: Gredos, 1988.

Aubert, Jean-Marie. Le droit romain dans l'œuvre de saint Thomas. Paris: Vrin, 1955.

Baciero, Francisco T. "El concepto de derecho subjetivo y el derecho a la propiedad privada en Suárez y Locke". Anuario filosófico 45, n. 2 (2012): 391421.

Belda, Juan. La Escuela de Salamanca y la renovación de la teología en el siglo XVI. Madrid: Biblioteca de Autores Cristianos, 2000.

Berman, Harold J. The Formation of the Western Legal Tradition. Cambridge, Mass: Harvard University Press, 1983. Traducido como La formación de la tradición jurídica de Occidente. Méjico: Fondo de Cultura Económica, 1996.

Beuchot, Mauricio. "La Ley y el Derecho en Santo Tomás". Revista de Filosofía 24, n. 2 (1996): 109-127.

Brett, Annabel S. Liberty, right and nature: individual rights in later scholastic thought. Cambridge: Cambridge University Press, 1997.

Brufau, Jaime. "La noción analógica del dominium en Santo Tomás, Francisco de Vitoria y Domingo de Soto". Salmanticensis 4, n. 1 (1957): 96-136.

Carpintero, Francisco. La ley natural. Historia de un concepto controvertido. Madrid: Encuentro, 2008. 
Casanova, Carlos A. "Guillermo de Ockham y el origen de la concepción nominalista de los derechos subjetivos". Cauriensia 11 (2016): 113-140.

Castillo, Genara. "Dominio y uso en la noción de pobreza de San Buenaventura en la Apología pauperum". Cauriensia 11 (2016): 141-156.

Cendejas, José Luis. "Economics, chrematistics, oikos and polis in Aristotle and St. Thomas Aquinas". The Journal of Philosophical Economics 10, n. 2 (2017): 5-46.

-. "Justicia, mercado y precio en Francisco de Vitoria". Revista Empresa y Humanismo 21, n. 2 (2018): 9-38.

Contreras, Sebastián. "La recepción de la doctrina tomista de la determinación del derecho en la segunda Escolástica". Revista Filosófica de Coimbra 45 (2013): 113-146.

Cruz, Juan. "La presencia de la ley natural en el ius gentium según Francisco de Vitoria". En Ley natural y niveles antropológicos: Lecturas sobre Santo Tomás, editado por J. Cruz. Pamplona: Universidad de Navarra, 2007.

- . "Reconducción práctica de las leyes a la ley natural: la epiqueya". Anuario Filosófico 41, n. 1 (2008): 155-179.

Decock, Wim. Theologians and Contract Law: The Moral Transformations of the Ius Commune (ca. 1500-1650). Leiden: Nijhoff, 2013.

Folgado, Avelino. "La controversia sobre la pobreza franciscana bajo el pontificado de Juan XXII y el concepto de derecho subjetivo". Pax iuris. Escurialensium utriusque studiorum excerpta (1959): 73-133.

- . "Evolución histórica del concepto del Derecho Subjetivo: estudio especial de los teólogos-juristas del siglo XVI". Anuario jurídico y económico escurialense 1 (1960): 17-329.

Francisco de Vitoria. La justicia. Editado por L. Frayle. Madrid: Tecnos, 2001.

-. De Legibus. Editado por S. Langella, J. Barrientos y P. García. Salamanca: Universidad de Salamanca, 2010.

-. Relecciones jurídicas y teológicas. Editado por A. Osuna, J. Cordero, M. Mantovani, R. Hernández, S. Langella y A. Martínez. Salamanca: San Esteban, 2017.

García Villoslada, Ricardo. La Universidad de París durante los estudios de Francisco de Vitoria (1507-1522). Roma: Universitatis Gregorianae, 1938.

Guzmán Brito, Alejandro. El derecho como facultad en la Neoescolástica española del siglo XVI. Madrid: Iustel, 2009.

- . "La doctrina del derecho-facultad o potestad de Francisco de Vitoria". En Francisco de Vitoria en la Escuela de Salamanca y su proyección en Nueva España, editado por V. Aspe y M. I. Zorroza. Pamplona: Eunsa, 2014.

Lázaro, Manuel. "Bases del uso, dominio y propiedad en la escuela franciscana: la relación con la realidad creada en El Francisco de San Buenaventura". Cauriensia 11 (2016): 197-220.

Prieto, Leopoldo. "La Ley natural y el orden político en John Locke". Revista española de Teología 69, n. 3 (2009): 383-440. 
-. "La noción de ley en Suárez y Locke". Daimon: Revista Internacional de Filosofía 71 (2017): 137-156.

Sierra, Restituto. El pensamiento social y económico de la Escolástica desde sus origenes al comienzo del Catolicismo social. Madrid: CSIC, 1975.

Tellkamp, Jörg Alejandro. "Ius est idem quod dominium: Conrado Summenhart, Francisco de Vitoria y la conquista de América". Veritas 54, n. 3 (2009): 34-51.

Tierney, Brian. The idea of natural rights. Grand Rapids, Michigan: William B. Eerdmans Publishing Company, 1997.

Tomás de Aquino. Suma de Teología. Madrid: Biblioteca de Autores Cristianos, 2001.

Truyol, Antonio. Historia de la filosofia del Derecho y del Estado. Madrid: Alianza, 1995.

Villey, Michel. La formation de la pensée juridique moderne. París: PUF, 1975. Vitoria, Francisco de. De Legibus. Editado por S. Langella, J. Barrientos y P. García. Salamanca: Universidad de Salamanca, 2010.

—. La justicia. Editado por L. Frayle. Madrid: Tecnos, 2001.

- Relecciones jurídicas y teológicas. Editado por A. Osuna, J. Cordero, M. Mantovani, R. Hernández, S. Langella y A. Martínez. Salamanca: San Esteban, 2017.

Zorroza, M. Idoya. "La definición del dominio según Alberto Magno". Cauriensia 8 (2013): 411-432.

- . "La relación del ser humano con el mundo, en forma de dominio, según Alejandro de Hales". Cauriensia 11 (2016): 315-346.

Zorroza, M. Idoya y Manuel Lázaro. "Uso, dominio y propiedad en la Escuela Franciscana". Cauriensia 11 (2016): 23-51.

José Luis Cendejas Bueno Instituto de Investigaciones Económicas y Sociales. Universidad Francisco de Vitoria Crta. Pozuelo a Majadahonda, km. 1,800 28223 Pozuelo de Alarcón, Madrid (España). https://orcid.org/0000-0001-8417-9455. 
